\title{
Infant siblings and the investigation of autism risk factors
}

\author{
Craig J Newschaffer ${ }^{1}$, Lisa A Croen ${ }^{2}$, M Daniele Fallin ${ }^{3}$, Irva Hertz-Picciotto ${ }^{4}$, Danh V Nguyen ${ }^{4}$, Nora L Lee ${ }^{1 *}$, \\ Carmen A Berry ${ }^{3}$, Homayoon Farzadegan ${ }^{3}$, H Nicole Hess ${ }^{5}$, Rebecca J Landa ${ }^{6}$, Susan E Levy ${ }^{7}$, Maria L Massolo ${ }^{2}$, \\ Stacey C Meyerer ${ }^{3}$, Sandra M Mohammed ${ }^{4}$, McKenzie C Oliver ${ }^{4}$, Sally Ozonoff ${ }^{8}$, Juhi Pandey ${ }^{7}$, Adam Schroeder $^{4}$ \\ and Kristine M Shedd-Wise ${ }^{4}$
}

\begin{abstract}
Infant sibling studies have been at the vanguard of autism spectrum disorders (ASD) research over the past decade, providing important new knowledge about the earliest emerging signs of ASD and expanding our understanding of the developmental course of this complex disorder. Studies focused on siblings of children with ASD also have unrealized potential for contributing to ASD etiologic research. Moving targeted time of enrollment back from infancy toward conception creates tremendous opportunities for optimally studying risk factors and risk biomarkers during the pre-, peri- and neonatal periods. By doing so, a traditional sibling study, which already incorporates close developmental follow-up of at-risk infants through the third year of life, is essentially reconfigured as an enriched-risk pregnancy cohort study. This review considers the enriched-risk pregnancy cohort approach of studying infant siblings in the context of current thinking on ASD etiologic mechanisms. It then discusses the key features of this approach and provides a description of the design and implementation strategy of one major ASD enriched-risk pregnancy cohort study: the Early Autism Risk Longitudinal Investigation (EARLI).
\end{abstract}

Keywords: Autism, Cohort, Epidemiology, Pregnancy, Prospective, Sibling, Study Design

\section{Review Introduction}

In 1957, Pearson and Kley published a prescient paper asserting that neuropsychiatric research should capitalize on the "tendency of particular abnormalities of behavior to run in families" (p. 406) so that "subpopulations defined in terms of genetic relationship to index cases... might be studied longitudinally..." (p. 418) [1]. They went on to note that such studies could be effective and economical for etiologic research. A 1976 review of the genetics of infantile autism and childhood schizophrenia [2] highlighted the potential of Pearson and Kley's highrisk design for etiologic research, but at that time the only such studies underway were investigations focusing on children of parents with schizophrenia (reviewed by Garmezy [3]). In the 1980s, prompted by the 1977 publication of Folstein and Rutter's seminal autism twin

\footnotetext{
* Correspondence: nllee@drexel.edu

'Department of Epidemiology and Biostatistics, Drexel School of Public Health, 1505 Race Street, Mail Stop 1033, Philadelphia, PA 19102, USA Full list of author information is available at the end of the article
}

study [4], siblings of autism probands increasingly were included in research samples; however, these were largely cross-sectional family studies in which researchers looked at recurrence risk and genetic segregation or linkage, not at prospective investigations where at-risk siblings were the subjects of principal interest. The first consideration of the prospective infant sibling study in autism, according to Yirmiya and Ozonoff, occurred in the mid-1980s, when US and UK researchers contemplated but rejected the idea because of concerns over heterogeneity in index proband diagnosis [5]. Once standard diagnostic tools were developed in the early 1990s, these projects moved forward with a focus firmly on phenotypic antecedents and very early signs of autism spectrum disorders (ASDs). Rogers [6] has since described the discovery of "the first behavioral characteristics that predict development of autism" as the "Holy Grail" (p. 126) of autism infant siblings research. Today there are 25 infant sibling research teams that are part of the High Risk Baby Siblings Research Consortium (BSRC) (Autism Speaks, Research on High Risk

\section{Biomed Central}


Baby Sibs: http://www.autismspeaks.org/science/initiatives/high-risk-baby-sibs), a voluntary network of projects with funding support from the National Institutes of Health and Autism Speaks, united in their common purpose of pursuing early phenotypic predictors of autism. The first papers derived from these efforts began to appear in 2005 and 2006 [7-10], and findings on emergence and trajectory of a range of developmental outcomes in high-risk infant sibling cohorts have been published steadily in the literature ever since.

Although discovering robust early phenotypic markers for autism to facilitate early detection and intervention remains a major autism research goal and an appropriate priority for infant sibling studies, the application of the high-risk infant sibling study design in autism etiology research has been underexplored. In this paper, we consider the role that infant sibling designs can play in autism risk factor research in the context of the evolving understanding of autism etiology and describe the design and methods which are being employed by a major high-risk sibling cohort study focused on autism etiology: the Early Autism Risk Longitudinal Investigation (EARLI).

\section{Current thinking on etiologic mechanisms in autism}

For decades, multiple lines of evidence have supported a substantial heritable component of autism etiology, including twin studies [4,11-14], familial risk studies [15-24], segregation analyses [24-27] and reported correlations between autism phenotypes and other congenital genetic disorders [28-32]. Modern genomic methods applied extensively to a variety of autism samples over the past decade have underscored the complexity of autism inheritance. A number of rare variants, for the most part de novo or inherited copy number variations (CNVs) [33-35], have been linked to autism by virtue of their apparent high penetrance. The teams leading three major autism genomewide association studies (GWASs) [33,36,37] have generated additional candidate genes, but have failed to replicate each other's findings. Consequently, lists of plausible autism candidate genes now include well over 100 genes $[38,39]$, including common genetic variants likely to have very small independent effects but potentially contributing to mechanisms with larger effects by interacting with each other or with rare genetic events [40]. Therefore, ongoing efforts are focused on the use of sophisticated analytic techniques applied to genomic data to identify common, biologically plausible pathways along which gene-gene interactions may take place [41-44].

In addition to an emphasis on gene-gene interactions, nearly all recent comprehensive reviews of autism genetics have cited interplay between genetic mechanisms and environmental exposures as another plausible contributor to the complexity of autism etiology [45-52]. The recent twin study conducted by Hallmayer et al. [53], which was larger than all its predecessors and the first done with autism cases confirmed using today's diagnostic tools, suggested a far larger role for environmental factors than did any earlier twin study. Furthermore, the fact that dizygotic twin concordance in their study was substantially larger than nontwin sibling recurrence risk reported in a recent large study of infant siblings [54] points to the prenatal period specifically as a period of special interest with respect to environmental influences. A potential role for epigenetic mechanisms in autism etiology $[55,56]$ also suggests additional ways in which environmental exposures can work in concert with genomic factors [57]. The need to move forward with more extensive investigation of environmental risk factors in autism is now widely accepted.

For most of the past 40 years, the investigation of environmental exposures has been sporadic. Several studies have provided evidence of highly elevated risk arising from congenital exposure to rubella $[58,59]$ and cytomegalovirus [60]. Similarly, some pharmacologic exposures in the prenatal period have been linked to autism, including thalidomide [61] and valproic acid [62-64]. More recent epidemiologic research has underscored the prenatal period as the most relevant etiologic window for autism environmental risk factors. For example, large studies have continued to find associations of autism risk with prenatal medication use [65,66] and infection [67]. Consistent with the infection finding, investigators in a small case-control study who capitalized on banked midpregnancy blood samples reported more frequent elevations in certain circulating inflammatory cytokines in mothers of children with autism than controls [68]. The first system-level analysis of the ASD brain transcriptome, in addition to an expected finding of synaptic dysfunction, has also suggested the presence of immune dysregulation [69], which is consistent with an earlier finding of neuroinflammation in the brains of individuals with autism [70]. However, whether these indications derived from autopsy studies reflect antecedent and potentially causal immunemediated events or downstream responses to other autism neuropathology is not yet clear.

Recently published systematic reviews of traditional obstetric and neonatal risk factors and autism reported that, for most of the individual risk factors considered (for example, contraception prior to pregnancy, maternal obstetric history, bleeding in pregnancy, gestational diabetes), either insufficient data were available or findings have not been well-replicated in the published literature [71-73]. This is not entirely unexpected, as many past studies have been based on small clinical samples without confirmation of diagnoses. However, the one factor with the most consistent association with increased autism risk across multiple studies is advanced parental age [74-80]. A variety of mechanisms might explain these 
associations, such as increased maternal complications during pregnancy or delivery, an accumulation of toxins affecting either the intrauterine environment or sperm development, and induced de novo mutation, of particular interest in the case of older fathers.

An interesting obstetric risk factor examined only recently with respect to autism is interpregnancy interval. An interval of less than one year between pregnancies was found in an initial report to be associated with more than a threefold increase in autism risk compared to intervals of three or more years $(\mathrm{OR}=3.4,95 \% \mathrm{CI}=$ 3.00 to 3.82 ). If short interpregnancy interval is an autism risk factor, it could implicate the intrauterine environment through nutritional depletion mechanisms [81]. Indeed, researchers in a large case-control investigation have reported intake of prenatal vitamin supplements in the periconception period (three months prior and one month after conception) to confer nearly a $40 \%$ reduction in risk $(\mathrm{OR}=0.62,95 \% \mathrm{CI}=0.42$ to 0.93$)$ [82]. This study was also notable because it contains the only published results to date explicitly supporting a geneenvironment interaction in autism with the apparent protection from maternal prenatal vitamin use magnified in the presence of certain genotypes involved in onecarbon metabolism [82].

Several investigations have examined air pollution, a complex mixture of exposures with wide-ranging toxicities, in relation to autism diagnoses. The designs of these ranged from a purely ecologic design that focused on industrial emissions of a single pollutant [83], to investigations that utilized individual-level diagnostic information in relation to modeled estimates of 25 hazardous air pollutants $[84,85]$, to distance to freeway, a strong indicator of ambient traffic-related pollutant levels [86]. This most recent study, a case-control design using clinically confirmed cases and individual-level exposure information, found living within one-quarter mile of a freeway at the time of delivery was associated with a 1.9-fold increased ASD risk (95\% CI $=1.04$ to 3.45). Researchers in earlier studies had used exposures occurring in the second year of life or later, which might not be the most etiologically relevant period.

Investigators in a number of other studies have also explored potential associations between autism diagnosis or autism-related phenotypes and pesticide exposure in the prenatal period. Residence in a location where application of organochlorine pesticides reached levels falling into the highest nonzero quartile during the eight-week pregnancy period after closure of the cranial neural tube was associated with a sixfold higher odds ratio of the child's developing autism $(\mathrm{OR}=6.1,95 \% \mathrm{CI}=2.4$ to 15.3) [87]. In a cohort study of primarily MexicanAmerican women, higher levels of metabolites for organophosphate pesticides were found to predict higher scores on an autism-related scale in 24-month-olds [88]. Studies attempting to replicate these findings are needed, though both types of compounds are plausibly linked to altered central nervous system development through endocrine disruption for the long-lasting organochlorines and through direct toxicity to the developing brain for the rapidly cleared organophosphates. Other commonly used pesticides have been associated with general neurodevelopmental deficits in prospective pregnancy cohorts [89-91] but have yet to be studied in autism.

With epidemiologic evidence consistently pointing to the prenatal period as a window of vulnerability to environmental exposures in autism, one might ask whether this is consistent with known autism neuropathology. Indeed, pathologic changes documented in autopsied brains of individuals with autism, including those found in the brainstem [92], cerebellum [93,94] and cortex [95], are indicative of a pathologic process originating in utero. Early brain overgrowth in autism, now documented in two longitudinal brain imaging studies [96,97], also suggests the presence of causal events occurring prior to birth, as does the recent brain transcriptomics report that autism brains lacked a pattern of differential gene expression across frontal and temporal cortical regions [69] that typically emerges during fetal development [98].

Could prenatal causal events be linked to exogenous exposures? It has long been established that prenatal brain development, including the fundamental processes of neuronal proliferation, migration, differentiation, synaptogenesis, gliogenesis, myelination and apoptosis, are susceptible to disruption by environmental exposures $[99,100]$. Subsequently, each of these fundamental processes has been considered in alternative models of autism pathology [101]. Some of the more recent work geared toward using autism genomics to identify biologic pathways has implicated synaptic homeostasis as a candidate common biological process in autism [102]. Although synapse formation begins in the third trimester, with synapse restructuring and connectivity development continuing well into postnatal life, animal models have shown that environmental exposures earlier in pregnancy can lead to impaired postnatal synaptic activity without obvious signs of disruption prenatally [103]. In addition, other genomics efforts focused on pathway detection, one using GWAS data and the other CNV data, have independently implicated impaired neuronal projection and axonal guidance $[35,44]$ as mechanisms of chief interest. These are environmentally sensitive processes beginning early in brain development $[104,105]$ that could certainly affect synaptic functioning downstream. Of course, the high likelihood of an in utero origin of autism in no way rules out the potential for etiologic and prognostic influences after birth, but 
the design and implementation of etiologic research focused on the prenatal period would appear strongly justified.

\section{Expanding the infant siblings approach to study autism etiology}

Infant sibling cohort studies, as implemented by members of the BSRC, enroll subjects younger than 18 months of age (many as young as 6 months of age) and carry out close longitudinal developmental follow-up, typically through 3 years of age. The design choice was motivated in part by expected recurrence rates that were many times higher than population autism prevalence and in part by the opportunity to observe early behavioral markers and better understand the complex early natural history of ASDs afforded by carefully measuring development prospectively. Both of these considerations are also quite germane to etiologic research. Yet, to maximally capitalize on infant sibling designs for etiologic research, it is necessary to extend cohort enrollment back to a point where the mother and the developing fetus can be followed prospectively through windows of potential etiologic vulnerability; in other words, by transforming the design to a high-risk pregnancy cohort. Each of these three features, increased event rate, prospective developmental assessment and shift to a pregnancy cohort design, is each discussed further below.

\section{Increased event rates}

When the BSRC was formed, published estimates for sibling recurrence risk ranged from $2 \%$ to $9 \%$ [13,15-22, 24,106]. Almost all of these studies considered recurrence of the more narrow autistic disorder diagnosis among siblings of a proband with autistic disorder, although the one study of probands and siblings with any autism spectrum diagnosis reported recurrence within the same range (5.3\%) [106]. In 2011, the BSRC published their first findings on ASD recurrence among 684 siblings of probands with an ASD followed from at least 18 months until at least 36 months [54]. In this large, recently ascertained sample, recurrence was $18.7 \%$ ( $95 \% \mathrm{CI}=13.3 \%$ to $25.5 \%)$. Even with recent population ASD prevalence estimates approaching 1\% [107], this implied 20-fold increase in sibling risk translates into increased numbers of cases in an enriched-risk sibling cohort, which increases power to detect associations between risk factors and ASD case status. In addition, the presence of higher levels of subthreshold impairment in toddler-age siblings of ASD probands has been documented. For example, Toth et al. [108] found significant differences in expressive and receptive language, composite IQ, adaptive behavior and social communication skills when they compared (1) 42 toddler-age siblings of ASD probands who did not meet ASD criteria based on the toddler-version Autism Diagnostic Interview-Revised (ADI-R) [109] and the Autism Diagnostic
Observation Schedule (ADOS) [110] to (2) 20 typically developing toddlers with no ASD family history. This suggests that there is a considerable range of impairment in the infant sibling cohort which should translate into increased power for risk factor analyses using dimensional as opposed to categorical phenotypic outcomes. Last, for conditions such as ASD where complex genetic mechanisms underlie increased baseline risk in the infant sibling sample, if a risk factor's effect is amplified by an unknown genotype or genotypes, the power to detect that risk factor is affected favorably [111].

\section{Prospective developmental assessment}

BSRC studies prospectively evaluate a range of developmental end points, including motor development, repetitive behaviors and abnormal movement patterns, social and emotional development, and response to joint attention [6]. The prospective developmental assessment in infant sibling studies can support etiologic research in two ways.

First, it allows for careful characterization of autismrelated dimensional phenotypes at early ages. As mentioned above, dimensional end points may prove revealing in ASD etiologic research, and perhaps studying variance of traits expressed very early in life could be the most revealing. To date, the dimensional measures used in etiologic research have been those developed from assessment of older children [112-114]. Should measures that are now being used in BSRC studies such as the Autism Observation Scale in Infants (AOSI) [115] provide valid early measurement of quantitative traits related to autism, enriched risk pregnancy cohort studies could incorporate these and utilize them as continuous end points in risk factor analyses.

Second, the longitudinal characterization of development could lead to the identification of distinct developmental trajectories which might themselves be considered as outcomes or could be used to stratify cases to test hypotheses that cases with different developmental trajectories could have distinct sets of risk factors. Landa and Garrett-Mayer [10] have already examined trajectories within high-risk siblings on a range of items measured by the Mullen Scales of Early Learning [116,117] among those meeting or not meeting research criteria for ASD at 24 months and found generally flatter trajectories in the group meeting these criteria, although they noted different patterns in different domains, such as the ASD group's deviating at 14 months on fine motor performance. Rozga et al. [118] reported no differences at six months of age in joint attention and requesting behaviors between high-risk siblings who went on to meet criteria for ASD and those who did not, but they found an emergence of differences at age 12 months. Another recent report, however, found head lag at 6 months of age to be predictive of social and communication impairment in high-risk siblings at age 
36 months [119]. As the size of infant sibling cohorts grows, BSRC investigative teams will be able to employ more sophisticated analyses to identify unique developmental trajectories, both within and across groups defined by whether ASD criteria are met.

\section{Shift to a pregnancy cohort design}

The returns from expanding infant sibling research can be amplified with the shift to a pregnancy cohort design. This approach allows for the prospective collection of detailed risk factor data during the critical etiologic windows, as opposed to retrospective collection that would be necessary if cohorts of siblings enrolled as toddlers were used for risk factor research. For a number of risk factors of general interest in the prenatal and neonatal periods, validation studies have demonstrated superiority of prospective versus retrospective data collection. For example, retrospective recall of depressive symptoms in pregnancy at just six months postpartum compared to prospective documentation showed only moderate agreement [120]. Recall of prenatal influenza infection symptoms (for example, persistent cough and fever) at delivery suggest underreporting compared to questionnaires completed between the 18th and 25th weeks of pregnancy [121]. Furthermore, there are concerns that parents of affected children will recall exposures during the prenatal period differently from parents of unaffected children, a phenomenon documented for certain exposures with respect to birth defects outcomes [122].

Certain findings that have begun to emerge regarding potential environmental risk factors for autism have limitations with respect to exposure measurement that could be obviated through prospective data collection in an expanded infant sibling study design. For example, one study of air pollution used modeled estimates covering the second year after birth [84]. Although the associations that were observed could contribute to the development of autism, exposures in earlier years (for example, during gestation or the first year after birth) might be of greater relevance. Other retrospective epidemiologic investigations have explicitly considered exposure during the prenatal period but have been limited to maternal residence at the time of birth as a proxy for exposure. For example, one retrospective study modeled prenatal exposure to pesticide based on distance from residence to reported date and location of agricultural applications of pesticides, but there was no individual-level measurement of exposure available [87]. The extent to which modeled exposure reflects actual exposure is a major question, with factors such as address changes, time spent at home, wind speed and drift, as well as absence of data on other exposure sources, contributing to potential misclassification. In addition, a number of studies have used administrative and medical databases to examine maternal prenatal use of medications. These data sources provide unbiased assessment for case-control comparisons and can address the relevant time periods, but they do not include data on over-the-counter medication use and do not take into account the fact that not all prescriptions are filled and not all filled prescription medications are actually taken by the patient. The infant sibling pregnancy cohort design has the potential to combine selfreport data on actual use of medications with medical records documentation on prescriptions from all sources.

The shift to a prospective cohort design also creates opportunities for implementation of cost-effective analytic strategies. When, for example, laboratory assays need to be completed on stored biologic specimens to generate risk factor data, these assays can be done on select subsamples from the cohort to conserve resources. Analyses can be limited to identified cases contrasted to a sample of noncases selected from the cohort at the time of case occurrence (incidence-density matched case-control design), a sample of noncases selected at the end of follow-up (cumulative incidence case-control design) or a sample of cohort members at baseline (case-cohort design). Such designs can often achieve close to comparable statistical power to analyses of data from the entire cohort [123]. Furthermore, when data on the full cohort can be used to inform the sampling of cases and controls (for example, two-stage or countermatching designs), additional statistical efficiencies can be achieved [124,125]. Alternatively, subsamples can be selected for more resource-intensive risk factor data collection (for example, through biomarkers or medical records abstraction), and the data derived from these subsamples can be used to correct measures of association based on risk factor data available in the full cohort or in case-control samples drawn from the full cohort [126].

The current thinking on autism etiology, where causal mechanisms are believed to be complex and multifactorial, is that a role for environmental factors is quite likely. However, research on environmental risk factors for autism faces significant challenges. Critical periods may occur early in brain development, and accurate measurement of environmental exposure during these critical periods will be important if causal contributions of these factors in the context of other contributors are to be identified. Etiologic heterogeneity in autism is likely, and identification of phenotypic correlates that mark distinct etiologies or, perhaps more realistically, can serve as useful endophenotypes for identifying certain causal components, is an active area of ongoing research. Given this situation, the expansion of infant sibling study designs for etiologic research where exposure data are captured prospectively during potentially relevant critical windows, outcomes are also prospectively characterized in detail, and event rates are higher than in population-based samples would appear to be one quite useful research approach. The sections that follow provide an overview 
of a large multisite investigation now underway that is implementing this study design.

\section{The EARLI Study as a model for risk factor research using a high-risk infant sibling design}

The EARLI Study was conceived to capitalize on expanding the infant siblings approach to autism etiologic research to realize many of the benefits described above. At least one other autism enriched-risk pregnancy cohort study that has many features in common with EARLI is now underway (the Markers of Autism Risk in BabiesLearning Early Signs (MARBLES) study: http://marbles. ucdavis.edu/). Below the EARLI research design, study population, recruitment and enrollment approach, risk factor data collection and outcomes evaluation strategy are described. Other investigators looking to replicate or incorporate aspects of this approach may benefit from the information provided herein. The EARLI Study parent protocol was reviewed and approved by the Drexel University Institutional Review Board (Project no. 71109; Protocol no. 17862). Local IRB approvals were also obtained at all EARLI Study sites. All study participants have undergone the consent process and signed the relevant consent or assent forms as appropriate for age and cognitive ability, or have had a parent consent on their behalf.

\section{Study design}

The EARLI Study is a multisite prospective pregnancy cohort study of mothers of children with an ASD diagnosis (autistic disorder, Asperger syndrome or pervasive developmental disorder not otherwise specified (PDD NOS)) who have become pregnant. Mothers are followed through pregnancy and delivery, then the pregnancy cohort evolves into an infant siblings cohort followed through age three years. Eligible pregnant women are enrolled by the 28th week of pregnancy, along with their biological child who has an ASD (the study proband). The biological father of the current pregnancy is also invited to enroll, although his participation is not a requirement for the participation of the mother and proband. Enrolled mothers are followed closely with intensive data and biosample collection. During the pregnancy, two to four study visits occur, which entail collection of serial biological samples from the mother and dust samples from the home. At the time of delivery, placental tissue, cord blood, heel stick blood and meconium are collected. Serial biological samples are collected postpartum from both the mother and the newborn baby (the study sibling). Clinical evaluations are conducted four times, beginning at six months of age and concluding when the child is three years old. The evaluations include autism and behavioral assessments and dysmorphology examinations. At the final study visit when the child is 36 months of age, the sibling's ASD status is determined for all participants, although individual diagnoses may have been made earlier, depending on when symptoms emerged. Throughout participation in the study (prenatally and postdelivery) selfreport data are collected from the mothers by using EARLI instruments and interviews that cover health behaviors, diet, reproductive and medical history, stress, depression, environmental and occupational exposures and medication use. Additional data are collected from the mother about the sibling during the first three years of life regarding general health, medications and medical care, specific symptoms or illnesses, diet, environmental exposures and developmental interventions. The EARLI Study is on pace to enroll 870 families over a 6-year period with plans in place to acquire follow-up data through 36 months from 630 of these families. Figure 1 shows key elements in EARLI Study data collection over the course of a family's participation

\section{Study population}

Women who meet the following criteria are eligible to participate in the EARLI Study: (1) have a biological child who has been diagnosed with an ASD, (2) competent to communicate in English (or, at two sites, in Spanish), (3) 18 years of age or older, (4) live within two hours of a study clinic and (5) are no more than 28 weeks pregnant. Women who meet the first four criteria and are not pregnant but trying to become pregnant or may become pregnant in the future (for example, unplanned pregnancy) may be followed and contacted regularly to ascertain their reproductive status. If they become pregnant during this preenrollment period, they can be rescreened for eligibility to enroll.

The EARLI Study is being implemented at four field sites in three distinct locations in the US, representing a racially, ethnically, and socioeconomically diverse study population (Table 1). The sites are based in major metropolitan areas (that is, Philadelphia, Baltimore, San Francisco Bay Area, and Sacramento) and catchment areas expand to a 2-hour radius of the study clinic at each site. Table 1 lists the range of county level demographics within the catchment areas.

\section{Participant recruitment}

Recruitment strategies vary by field site to accommodate the unique resources available to each site. Generally, the target population is mothers with a young child (2 to 12 years old) with ASD, who would be more likely to become pregnant again than a mother with an older child. For example, for the Pennsylvania and Maryland sites, a primary strategy for reaching potentially eligible mothers is distribution of information through the early intervention and special education systems. The northern California site at the University of California, Davis, identifies and reaches potentially eligible mothers primarily through the state's Department of Developmental Services, whereas the Kaiser Permanente site in northern California can identify Kaiser Permanente members 


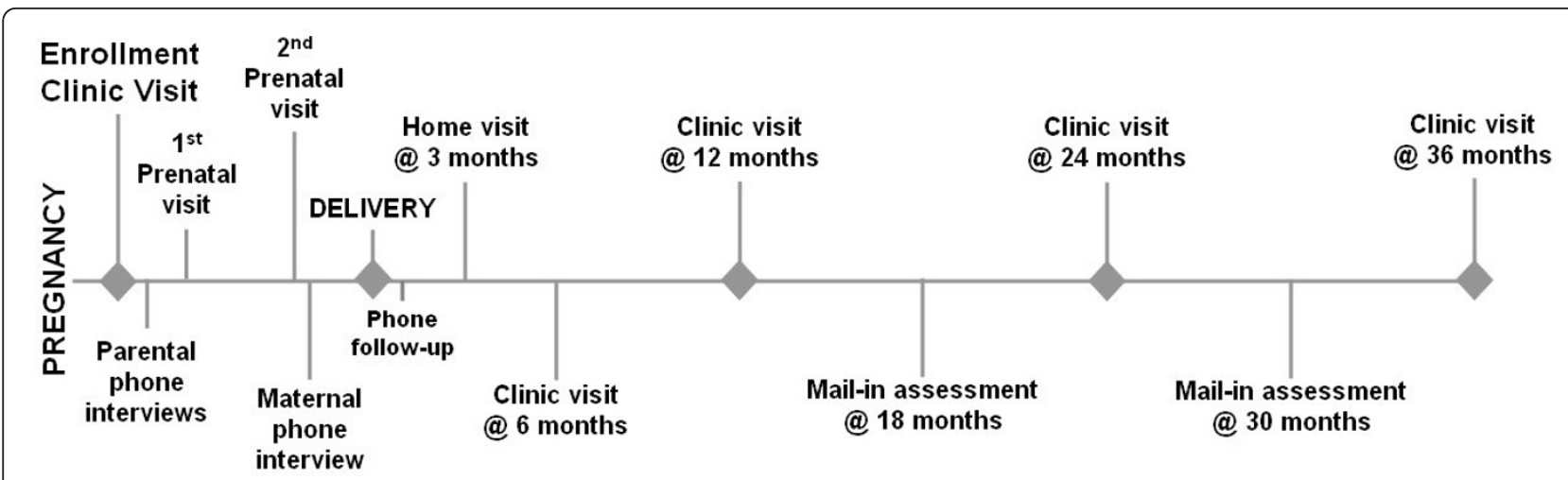

Figure 1 Early Autism Risk Longitudinal Investigation Study data collection points over the course of participation.

who become newly pregnant and already have children with autism. Clinical service providers in the catchment areas, including ASD evaluation and diagnostic centers, developmental pediatricians and mental health service providers, are also engaged at each site to reach potentially eligible women. The researchers in the EARLI Study have not focused on establishing relationships with providers serving the general population of pregnant women (for example, obstetricians, nurse midwives) or children (for example, general pediatricians) for individual-level outreach but will make available general information about the EARLI Study as requested. All field sites carry out supplementary recruitment efforts through staffed information tables at autism events and through advocacy organizations' websites, listservs and newsletters. Reinforcing information about the EARLI Study through multiple channels increases the chance that mothers of reproductive age who have children with ASD, at a later time when they are pregnant, will remember and consider enrolling in the EARLI Study. To that end, EARLI also maintains an active presence in social media, including Facebook [127] and YouTube [128] and has a web presence [129] that includes content geared toward potentially eligible mothers as well as enrolled participants. Given this recruitment approach, it is possible that participating families might differ from their respective area source population on factors related to the extent of connection to service systems and the degree of immersion in the autism community. To introduce bias, such selection needs to be differential with respect to both exposure and outcome. Although these selection effects could be associated with certain exposure profiles of interest, independent associations with ASD risk, though conceivable, seem less likely. EARLI Study sites, to varying degrees, will be able to explore differences between participating families and source populations. All sites can compare basic characteristics of participating families with families in the region receiving services for a young child with ASD, but only the Kaiser Permanente site has the ability to identify the subgroup in the source population who are becoming pregnant.

\section{Enrollment and retention}

When a pregnant mother of a child with autism begins the enrollment process, proband diagnosis first needs to be confirmed. In families with more than one child with

Table 1 Range of the percentage of demographic characteristics among the counties in EARLI Study field site areas ${ }^{a}$

\begin{tabular}{|c|c|c|c|}
\hline \multirow[b]{2}{*}{ Characteristics } & \multicolumn{3}{|c|}{ County Low and High Percentages within Field Site Catchment Areas } \\
\hline & $\begin{array}{l}\text { SE Pennsylvania ( } 13 \text { counties in } \\
\text { PA, NJ, DE) }\end{array}$ & $\begin{array}{l}\text { NE Maryland ( } 9 \\
\text { counties in MD) }\end{array}$ & $\begin{array}{l}\text { N. California ( } 25 \\
\text { counties in CA) }\end{array}$ \\
\hline White & $41.0 \%$ to $89.2 \%$ & $19.2 \%$ to $92.9 \%$ & $43.0 \%$ to $91.4 \%$ \\
\hline Black or African-American & $3.6 \%$ to $43.4 \%$ & $3.2 \%$ to $64.5 \%$ & $0.4 \%$ to $14.7 \%$ \\
\hline Asian & $0.8 \%$ to $8.9 \%$ & $1.1 \%$ to $14.4 \%$ & $1.1 \%$ to $33.3 \%$ \\
\hline Hispanic or Latino & $3.0 \%$ to $18.8 \%$ & $2.6 \%$ to $17.0 \%$ & $8.5 \%$ to $55.4 \%$ \\
\hline $\begin{array}{l}\text { Language other than English spoken at home (5 years } \\
\text { or older) }\end{array}$ & $7.4 \%$ to $24.8 \%$ & $5.2 \%$ to $35.8 \%$ & $6.5 \%$ to $51.2 \%$ \\
\hline Families below poverty ${ }^{c}$ & $4.2 \%$ to $22.9 \%$ & $4.5 \%$ to $22.9 \%$ & $7.2 \%$ to $24.6 \%$ \\
\hline $\begin{array}{l}25+\text { years old with educational attainment 9th to 12th } \\
\text { grade, no diploma }{ }^{+}\end{array}$ & $7.8 \%$ to $28.8 \%$ & $5.7 \%$ to $31.6 \%$ & $6.6 \%$ to $33.0 \%$ \\
\hline
\end{tabular}

${ }^{a}$ Data are derived from the 2010 US census. ${ }^{b} 2005$ to 2009 for all counties; 2000 for Philadelphia City and Baltimore City. ${ }^{\text {c } 2009}$ for all counties; 1999 for Philadelphia City and Baltimore City. EARLI, Early Autism Risk Longitudinal Investigation. 
ASD, the study proband is the child who is the closest biologic relation to the future sibling, or, if both are the same biologic relation to the future sibling, then a child with an autistic disorder diagnosis would be enrolled over a child with Asperger syndrome or PDD NOS. The mother is enrolled in the study after consenting at the enrollment clinic visit, and the study proband's eligibility is confirmed by a valid ADOS [109] and an age-appropriate IQ test (for example, Mullen Scales of Early Learning for infancy to 68 months of age; or the Kaufman Brief Intelligence Test, Second Edition, for ages 4 years to 90 years). Fathers may enroll at the enrollment clinic visit, or during a home visit if they are not at the enrollment clinic visit.

As Figure 1 illustrates, the EARLI Study involves extensive data collection, so investigators strive to maximize retention by being as flexible as possible. Both online and paper versions of most questionnaires and documents are available, and home visits and flexible visit scheduling is accommodated when possible. Of the first 177 families enrolled in the study, $97.2 \%$ are still participating. Variability in the time of data collection creates challenges and opportunities for research but is also a reality of intensive, prospective follow-up of this study population. Retention in the EARLI Study is also driven by the prospective developmental follow-up offered for the at-risk siblings. EARLI Study sites provide families with summaries of research evaluations, discuss questions with families, provide information on local resources for families concerned with their child's development and make referrals for services for affected siblings. Upon enrollment, the EARLI Study also provides families with a specially developed social storybook about the impending arrival of a baby sibling that parents can use in interactions with the proband. EARLI Study investigators stay connected with enrolled families as a group through the study website, Facebook and study newsletters.

\section{Risk factor data collection}

The EARLI Study approach to risk factor data collection is comprehensive, involving multimodal self-report, records review, direct observation and biologic and environmental sample collection. This approach allows for analysis of risk factor characterization during specific suspected etiologic windows, comparison of risk factor data from multiple sources, estimation of risk factor-outcome associations motivated by specific hypotheses and discovery-oriented work intended to reveal first evidence for novel risk factors. Table 2 provides a broad overview of data collection modes by subject. Self-reports are provided by both parents at enrollment and extend back to the preconception period. During pregnancy, mothers provide reports in weekly pregnancy diaries regarding exposures that are more challenging to recall retrospectively and are extensively interviewed twice (approximately 625 items) to collect information retrospectively on less time-sensitive information in pregnancy. Selected self-report questionnaires are also used to cover specific domains such as diet and depressive symptoms. Table 3 summarizes the range of risk factor domains covered by EARLI Study self-report data collection.

Biosampling in the EARLI Study is comparably extensive. Fathers and probands provide biosamples at enrollment. Venous blood is collected from both, and fathers are also provided with a home semen collection kit. Biosampling in mothers begins at enrollment with the collection of blood, first void urine and hair. Mothers provide these samples at least once and as many as three additional times during pregnancy, depending on how early in the pregnancy enrollment occurred. The EARLI Study makes efforts to work closely with mothers, obstetricians and/or birth hospitals to facilitate the collection of delivery samples. Umbilical cord blood and placental samples are collected as close to delivery as possible. Four placental punch biopsies, two from the maternal and two from the fetal side, are taken and placed into cryovials of RNAlater $^{\mathrm{TM}}$ (QIAGEN, Valencia, CA, USA). The remaining placental tissue is fixed in formalin. Heel stick cards are left at the hospital, and newborn blood is collected by hospital staff after neonatal screening whenever possible without an additional heel stick. Mothers are provided with collection kits for breast milk, meconium and diaper urine. Manually expressed breast milk is collected at one week

Table 2 EARLI Study data collection modes by subject ${ }^{a}$

\begin{tabular}{|c|c|c|c|c|c|c|}
\hline \multirow[b]{2}{*}{ Data collection mode } & \multicolumn{3}{|c|}{ Mother } & \multirow[b]{2}{*}{ Father } & \multirow[b]{2}{*}{ Proband } & \multirow[b]{2}{*}{ Sibling } \\
\hline & Preconception & Prenatal & Perinatal & & & \\
\hline Self-report retrospective & $x$ & $x$ & & $x$ & $x$ & $x$ \\
\hline Self-report prospective & & $x$ & & & & $x$ \\
\hline Biologic sampling & & $x$ & $x$ & $x$ & $x$ & $x$ \\
\hline Direct observation (home environment) & & $x$ & & & & $x$ \\
\hline Environmental sampling & & $x$ & & & & $x$ \\
\hline Medical records ${ }^{a}$ & $x$ & $x$ & $x$ & $x$ & $x$ & $x$ \\
\hline
\end{tabular}

${ }^{a}$ The EARLI Study secures medical record releases for each participant and will pursue abstraction as needed to support individual analyses. EARLI, Early Autism Risk Longitudinal Investigation. 
Table 3 Domains of risk factor data collected from interviews, diaries and other self-report forms

\begin{tabular}{|c|c|c|c|}
\hline Risk factor domains & Interviews & Diaries & $\begin{array}{l}\text { Other self-report } \\
\text { forms } \mathrm{s}^{\mathrm{a}}\end{array}$ \\
\hline Demographics & $M, F$ & & $\mathrm{~F}$ \\
\hline Medication exposure & $M, F$ & $M, S$ & $M, F, S$ \\
\hline Medical conditions & M & M & $M, F, S$ \\
\hline Pesticides & & S & $M, S$ \\
\hline Diet & M & S & M \\
\hline $\begin{array}{l}\text { Home environmental } \\
\text { exposures }\end{array}$ & M & $M, S$ & $M, F$ \\
\hline Health behaviors/lifestyle & & S & $M, F$ \\
\hline $\begin{array}{l}\text { Mental condition/history/ } \\
\text { symptoms }\end{array}$ & M & M & $M, F, S$ \\
\hline Vaccine history & & $M, S$ & \\
\hline Personal product use & M & $M, S$ & M \\
\hline Anthropometrics & M & M & M \\
\hline Medical procedures & M & $M, S$ & $M, F$ \\
\hline Occupational history & & & $M, F$ \\
\hline
\end{tabular}

Includes the following forms: Home Walkthrough Survey, Maternal Interview Update, CHARGE Family Medical History Form, Dietary History Questionnaires (preconception, 1 to 20 weeks, 21 to 36 weeks and postnatal), Health Behaviors Questionnaires (preconception, pregnancy and paternal), Paternal Interview, 24-Hour Recalls (food and environment), Stress and Depression Surveys, Postnatal Diaries, Blood Draw Information Form, Maternal Medical History, Post-Partum Environmental Exposures and Dust Field Log. M, mother; $F$, father; S, sibling.

(postcolostrum) and twelve weeks. Nighttime diaper urine is collected from a sterile gauze pad at one week. Study staff visit the family at three months and pick up biologic samples the family has retained in the home freezer and also collect clean-catch urine from the infant sibling at that time. At the six-month clinic visit, mothers again provide blood, urine and hair samples, and a first venous blood sample, another diaper urine sample and a hair sample are taken from the infant sibling. Biosampling concludes with infant siblings' providing venous blood and diaper/pull-up pad urine samples during the 12- and 24month follow-up clinic visits. This continued longitudinal sampling of blood and urine in siblings provides opportunities for assessment of early life exposures and also creates the potential to investigate peripheral biomarkers of early outcome. Biosampling time points by participant and sample type are summarized in Table 4.

Biosample-processing decisions in EARLI were made by balancing timeliness, logistics and cost while being mindful of the nature of each sample. Processing on-site is minimal for venous blood, limited to centrifuging as dictated by tube type, with samples shipped next-day delivery to the central laboratory and biorepository (CLBR). The complement of tube types used varies slightly by subject and visit, but generally ethylenediaminetetraacetic acid (EDTA) and serum separator tubes (SSTs) are used during each draw with the PAXgene Blood RNA Kit (QIAGEN, Valencia, CA, USA), prescreened metal EDTA and cell preparation tubes (CPTs) interspersed. Maternal first void and infant sibling urine are aliquoted and frozen on-site and shipped monthly on dry ice to the CLBR. Diaper pad urine, meconium and breast milk are also batch-shipped frozen to the CLBR. Semen samples are collected by the father and frozen at home for a minimum of 24 hours, then shipped directly to the CLBR. Dried heel stick cards are sent back to the sites, where they are stored at ambient temperature and batch-shipped, as are hair samples, to the CLBR. Blood sample processing at the CLBR generates a repository of multiple aliquots of stored plasma, serum, whole blood, extracted DNA and peripheral blood mononuclear cells (PBMCs), including aliquots processed and saved to allow for establishment of cell lines.

Researchers in the EARLI Study also assess the home environment once during pregnancy and at the threemonth postpartum home visit. The home assessment includes a walk-through survey with questions related to how the family distributes their indoor time across rooms in the home, characteristics of the principal rooms where the mother and infant sibling spend most

Table 4 EARLI biosampling time points by biosample and participant type

\begin{tabular}{|c|c|c|c|c|}
\hline Sample & Mother & Father & Proband & Infant sibling \\
\hline Blood & $\begin{array}{l}\text { E, pre-2nd, pre-3rd, post- } 6 \\
\text { months }\end{array}$ & $\mathrm{E}$ & $E$ & Post -6 months, post-12 months, post- 24 months \\
\hline Hair & $\begin{array}{l}\text { E, pre-2nd, pre-3rd, post- } 6 \\
\text { months }\end{array}$ & & & Post -6 months, post- 12 months, post- 24 months \\
\hline Urine & $\begin{array}{l}\text { E, pre-2nd, pre-3rd, post- } 6 \\
\text { months }\end{array}$ & & & $\begin{array}{l}\text { Post- } 1 \text { week, post- } 3 \text { months, post- } 6 \text { months, post- } 12 \text { months, post- } 24 \\
\text { months }\end{array}$ \\
\hline Semen & & E & & \\
\hline Placenta, cord blood & D & & & \\
\hline $\begin{array}{l}\text { Heel stick blood, } \\
\text { meconium }\end{array}$ & & & & $\mathrm{D}$ \\
\hline Breast milk & Post- 1 week, post- 3 months & & & \\
\hline
\end{tabular}

${ }^{a} D$, delivery; E, enrollment; EARLI, Early Autism Risk Longitudinal Investigation; pre-2nd, second prenatal visit; pre-3rd, third prenatal visit; post-1 week, 1 week postnatal; post-3 months, 3 months postnatal; post- 6 months, 6 months postnatal; post- 12 months, 12 months postnatal; post- 24 months, 24 months postnatal. 
of their time, cleaning product use, and indoor and outdoor spray and pesticide use. A dust sample is also collected from the main living area by using a Eureka Mighty Mite vacuum cleaner (Eureka Co, Charlotte, NC, USA) following a protocol used in multiple previous studies [130-134]. House dust is an easily collected reservoir comprising compounds such as pesticides, plasticizers and flame retardants and has served as a marker of exposure in several epidemiologic studies [135-139].

Finally, the members of the EARLI Study team obtain medical record release forms from all participants, and they plan to abstract records as needed to assess exposure related to clinical domains where self-report data have inherent limitations and/or where medical records data might validate recall. Items of particular interest include specific clinical tests or results in mothers (for example, type of ultrasound, blood pressure, blood glucose levels) and newborns (for example, oxygen saturation values, fetal heart rate tracings, newborn screening results) and details regarding indications and dates for procedures and medications.

\section{Outcome data collection}

Infant siblings are followed to age 36 months, with clinical assessment of ASD-related behaviors and other developmental domains occurring at 6, 12, 18, 24 and 36 months. Behavioral outcome assessment tools are summarized in Table 5 . The assessment protocol was designed to measure core autism and related phenotypes, enabling investigation of dichotomous end points, continuous outcomes and developmental trajectories. Direct observation, interview and parent-report measures are all used. The autism-specific direct observation tool used at ages 6 and 12 months is the AOSI [115]. Initial evaluation of this tool suggested that total scores are the most robust predictor of autism at 24 months of age [115], and work is ongoing to assess the dimensional measure utility of the AOSI as well as the predictive ability of both total score and specific items [140]. At ages 24 and 36 months, the ADOS is administered. At these ages, the ADOS has high sensitivity for both autism and ASD, along with moderate specificity, using the revised scoring algorithm [141]. An algorithm has also recently been developed for converting raw ADOS scores to a 10-point severity measure (with scoring also dependent on ADOS module, classification and age) [142]. At 36 months, the ADI-R is also administered. The addition of the ADI-R to ADOS results for determining a final classification markedly improves classification specificity without major sacrifices in sensitivity [141]. The Social Responsiveness Scale (SRS) [143,144] has been shown to have useful dimensional scale properties in first-degree relatives of affected probands $[145,146]$. The EARLI researchers administer the Preschool Version (for 3-year-olds) of the SRS to infant siblings at age 36 months. At enrollment, the Adult

Table 5 EARLI behavioral outcome assessments by infant sibling follow-up point ${ }^{a}$

\begin{tabular}{|c|c|c|c|c|c|}
\hline Assessments & $\begin{array}{l}\text { 6-month clinic } \\
\text { visit }\end{array}$ & $\begin{array}{l}\text { 12-month clinic } \\
\text { visit }\end{array}$ & $\begin{array}{l}\text { 18-month } \\
\text { mailing }\end{array}$ & $\begin{array}{l}\text { 24-month clinic } \\
\text { visit }\end{array}$ & $\begin{array}{l}\text { 36-month clinic } \\
\text { visit }\end{array}$ \\
\hline \multicolumn{6}{|l|}{ Autism assessments } \\
\hline AOSI (Autism Observation Scale for Infants) & $x$ & $x$ & & & \\
\hline $\begin{array}{l}\text { ADI-R (Autism Diagnostic Interview- } \\
\text { Revised) }\end{array}$ & & & & & $x$ \\
\hline $\begin{array}{l}\text { ADOS (Autism Diagnostic Observation } \\
\text { Schedule) }\end{array}$ & & & & $x$ & $x$ \\
\hline SRS (Social Responsiveness Scale) & & & & & $x$ \\
\hline \multicolumn{6}{|l|}{ Other behavioral assessments } \\
\hline $\begin{array}{l}\text { CSBS-DP (Communication and Symbolic } \\
\text { Behavior Scales Developmental Profile) } \\
\text { Infant/Toddler Checklist }\end{array}$ & $X$ & $x$ & $x$ & & \\
\hline CBCL (Child Behavior Checklist) & & & & & $x$ \\
\hline $\begin{array}{l}\text { MCDI (MacArthur Communicative } \\
\text { Development } \\
\text { Inventories) }\end{array}$ & & $x$ & $x$ & $x$ & \\
\hline $\begin{array}{l}\text { M-CHAT(Modified Checklist for Autism in } \\
\text { Toddlers) }\end{array}$ & & & $x$ & $x$ & \\
\hline Mullen Scales of Early Learning & X & $x$ & & $x$ & $x$ \\
\hline Rothbart Temperament Questionnaires & $X$ & & & & $x$ \\
\hline SEQ (Sensory Experiences Questionnaire) & & $x$ & & $x$ & $x$ \\
\hline $\begin{array}{l}\text { Vineland II } \\
\text { (Vineland Adaptive Behavior Scales, } 2^{\text {nd }} \\
\text { edition) }\end{array}$ & $X$ & $x$ & $x$ & $x$ & $x$ \\
\hline
\end{tabular}

${ }^{a}$ EARLI, Early Autism Risk Longitudinal Investigation. 
Research Version of the SRS is administered to the parents, who each report on their spouse, and the Preschool Version or the Autoscore Form Parent Report is administered to the proband, depending on the proband's age.

In addition, EARLI incorporates other behavioral measures that have been demonstrated to have value in phenotyping high-risk infant siblings. The Mullen Scales of Early Leaning, in addition to providing data on subdomains of particular interest, such as nonverbal IQ [117] and motor functioning [147], has also been used more broadly to characterize developmental trajectory in highrisk siblings $[10,148]$. The Vineland Adaptive Behavior Scales $[149,150]$ have been employed effectively with infant sibling data to differentiate functional phenotypes [148]. In addition, other tools can improve the richness of available data on early language and communication (Communication and Symbolic Behavior Scales Developmental Profile Infant/Toddler Checklist (CSBS DP ITC) $[151,152]$ and MacArthur-Bates [153,154]), sensory impairments [155], temperament (Rothbart) [156,157] and emergent maladaptive behavioral and emotional problems (Child Behavior Checklist (CBCL) $[158,159]$ ).

The EARLI Study also incorporates data collection regarding physical features and medical comorbidities. At age 36 months, a dysmorphology assessment is completed following a protocol adapted from the Study to Explore Early Development (SEED) [160]. This examination involves direct measurement of growth parameters (height, weight, head circumference and body mass index) and evaluation of dysmorphology. A trained member of the research team photographs the child's face and ears (front of face, right and left profiles of ears, and left and right three-quarters images showing each ear and the face), hands (both sides and a hand scan of the palms), feet (weight-bearing and not), teeth, any skin findings and two posterior views of the head to identify hair whorl and hairline. For the facial photographs, a size reference sticker is included. Parents are queried about the presence of physical anomalies and whether the child has ever had corrective surgery, has been diagnosed with any syndromes or has had any genetic testing. This same assessment is administered to the proband at the time of enrollment. At the 6-, 12- and 24-month study visits, the sibling also receives a brief physical examination to capture infant growth parameters (length, weight, head circumference and weight-tolength ratio), and the parents are asked the same set of questions on genetic testing, anomaly or syndrome diagnoses and corrective surgeries. Finally, a comprehensive medical history questionnaire completed by the mother addresses any medical problems and procedures that have occurred during the course of the infant sibling's first three years of life. As mentioned above, medical records releases are obtained for the infant sibling to allow followup for more details on any problems or procedures noted.

The design, recruitment strategy and data collection approach of the EARLI Study are intended to build a data platform upon which a wide range of prenatal and early life risk factor investigations will be launched. The rich combination of prospectively collected exposure and outcome data should allow for analyses that incorporate strong confounder control and limit exposure misclassification and have a range of data sufficient to approach complex questions of effect modification and mediation along risk pathways. Although EARLI's sample size is large in relation to other infant sibling studies, there will no doubt be challenges related to sample size, and, as mentioned previously, attention to designing analytic contrasts in ways that maximize efficiency and incorporation of dimensional as well as categorical outcomes will likely prove helpful in this regard.

\section{Conclusions}

Infant sibling studies have already played a major role in autism research over the past decade, improving our understanding of the complex early developmental trajectory of autism, providing exciting leads on approaches for early detection and documenting recurrence risk under today's diagnostic standards. Extension of the infant siblings design to intervention studies is already underway, with behavioral interventions being tested in high-risk siblings with very early signs of developmental issues (see, for example, the Infant Start Study [161]).

As described above, the potential for the extension of the design to autism risk factor research is great. The EARLI Study has substantial potential to contribute to risk factor research on its own; however, there is also added potential through collaborations and extensions of the EARLI project. The EARLI Study team is working with researchers in the Infant Brain Imaging Study (IBIS) [162], another extension of the infant siblings design adding prospective brain imaging to developmental follow-up, to conduct coordinated genomics on both EARLI and IBIS study samples to undertake pooled analyses of genetic variants and developmental phenotypes. Because both IBIS and EARLI are collecting phenotype data on infant siblings longitudinally from ages 6 to 36 months, they have a unique opportunity to examine genetic relationships with developmental trajectories in addition to autism per se. Moreover, the genetic data will support independent analyses of genotypes and brain imaging in the IBIS sample and gene-environment interaction in EARLI. EARLI has also partnered with experts in epigenetics to explore the potential role of epigenetic mechanisms in autism and the possible link between epigenetics and environmental risk factors. Through a National Institutes of Health Roadmap 
program award, EARLI data will be analyzed in parallel with data from two other birth cohort studies to examine relationships between DNA methylation (DNAm) and prenatal exposures, as well as between DNAm, birth outcomes and early childhood developmental milestones. As the EARLI cohort develops, other opportunities to take advantage of the rich available data in this unique sample are sure to arise.

Last, in addition to enriched risk pregnancy cohorts such as EARLI, it should be noted that worldwide there are several population-based pregnancy cohort studies, in which recruitment is not geared to enriched-risk families, that have made autism an identified outcome of interest [163-167]. These studies range in size from the 1,200subject Hamamatsu Birth Cohort in Japan [168] to the 110,000-subject Autism Birth Cohort Study [167] that has recently been incorporated into the Norwegian Mothers and Babies Study [169]. Researchers in population-based cohort studies can explore the generalizability of findings that emerge from enriched-risk designs and could also become engaged with enriched-risk cohorts in coordinated analytic efforts to study rare prenatal exposures or complex etiologic mechanisms.

As research on autism risk factors and risk biomarkers during the pre-, peri- and neonatal periods intensifies during the coming decade, enriched-risk cohort designs, along with large case-control studies $[170,171]$ and population-based cohort designs, can be expected to play an important role. This expansion of autism infant sibling studies, which have emerged during the past five years as extremely valuable tools with which to improve understanding of the early-life autism phenotype, to address etiologic questions will, we hope, mark an important step toward identification of avoidable or modifiable factors that will ultimately help reduce the population morbidity and impact of autism on quality of life.

\section{Abbreviations \\ ADI-R: Autism Diagnostic Interview-Revised; ADOS: Autism Diagnostic Observation Schedule; AOSI: Autism Observation Scale for Infants; ASD: Autism spectrum disorder; BSRC: Baby Siblings Research Consortium; CBCL: Child Behavior Checklist; CLBR: Central laboratory and biorepository; CNV: Copy number variation; CPT: Cell preparation tube; CSBS DP: Communication and Symbolic Behavior Scales Developmental Profile; DNAm: DNA methylation; EARLI: Early Autism Risk Longitudinal Investigation; EDTA: Ethylenediaminetetraacetic acid; GWAS: Genomewide association study; IBIS: Infant Brain Imaging Study; MARBLES: Markers Of Autism Risk In Babies- Learning Early Signs; PBMC: Peripheral blood mononuclear cell; PDD NOS: Pervasive developmental disorder not otherwise specified; SEED: Study to Explore Early Development; SST: Serum separator tube; SRS: Social Responsiveness Scale.}

\section{Acknowledgements}

The EARLI Study is funded by the National Institute of Environmental Health Sciences, the National Institute of Mental Health, the National Institute of Child Health and Human Development, and the National Institute of Neurologic Disease and Stroke (R01 ES016443), with additional funding from Autism Speaks (AS 5938).

\section{Author details}

'Department of Epidemiology and Biostatistics, Drexel School of Public Health, 1505 Race Street, Mail Stop 1033, Philadelphia, PA 19102, USA. ${ }^{2}$ Kaiser Permanente Division of Research, 2000 Broadway, Oakland, CA 94612, USA. ${ }^{3}$ Department of Epidemiology, Johns Hopkins Bloomberg School of Public Health, 615 N Wolfe Street, Baltimore, MD 21205, USA. ${ }^{4}$ Department of Public Health Sciences, University of California, Davis, CA 95616, USA. ${ }^{5}$ Kaiser Permanente San Jose Medical Center, 6620 Via Del Oro, San Jose, CA 95119, USA. ${ }^{6}$ Kennedy Krieger Institute, 3901 Greenspring Avenue, 2nd Floor, Baltimore, MD 21211, USA. ${ }^{7}$ Center for Autism Research, The Children's Hospital of Philadelphia, 3535 Market Street, Suite 860, Philadelphia, PA 19104, USA. ${ }^{8}$ The MIND Institute, UC Davis Medical Center, 2825 50th Street, Sacramento, CA 95817, USA.

\section{Authors' contributions}

CJN, LAC, MDF, and IHP made substantial contributions to the conception and design of the study, and drafted and revised the manuscript. DVN, SMM, and AS participated in data coordination, collection, and analysis, and revised the manuscript. NLL, CAB, MLM, MCO, and KMSW contributed to the implementation of the study and contributed to manuscript revisions. HF and SCM participated in the design and coordination of biosampling aspects of study implementation, and revised the manuscript. HNH, SEL, RJL, SO, and JP contributed to the study design and clinical data collection, and contributed to the manuscript draft and revisions. All authors read and approved the final manuscript.

\section{Competing interests}

The authors declare that they have no competing interests.

Received: 6 November 2011 Accepted: 18 April 2012

Published: 18 April 2012

\section{References}

1. Pearson JS, Kley IB: On the application of genetic expectancies as agespecific base rates in the study of human behavior disorders. Psychol Bull 1957, 54:406-420.

2. Hanson DR, Gottesman II: The genetics, if any, of infantile autism and childhood schizophrenia. J Autism Child Schizophr 1976, 6:209-234.

3. Garmezy N: Children at risk: the search for the antecedents of schizophrenia. Part II: ongoing research programs, issues, and intervention. Schizophr Bull 1974, 9:55-125.

4. Folstein S, Rutter M: Infantile autism: a genetic study of 21 twin pairs. J Child Psychol Psychiatry 1977, 18:297-321.

5. Yirmiya N, Ozonoff S: The very early autism phenotype. J Austim Dev Disord 2007, 37:1-11.

6. Rogers SJ: What are infant siblings teaching us about autism in infancy? Autism Res 2009, 2:125-137.

7. Zwaigenbaum L, Bryson S, Rogers T, Roberts W, Brian J, Szatmari P: Behavioral manifestations of autism in the first year of life. Int I Dev Neurosci 2005, 23:143-152.

8. Yirmiya N, Gamliel I, Pilowsky T, Feldman R, Baron-Cohen S, Sigman M: The development of siblings of children with autism at 4 and 14 months: social engagement, communication, and cognition. J Child Psychol Psychiatry 2006, 47:511-523.

9. Mitchell S, Brian J, Zwaigenbaum L, Roberts W, Szatmari P, Smith I, Bryson S: Early language and communication development of infants later diagnosed with autism spectrum disorder. J Dev Behav Pediatr 2006, 27: S69-578.

10. Landa R, Garrett-Mayer E: Development in infants with autism spectrum disorders: a prospective study. J Child Psychol Psychiatry 2006, 47:629-638.

11. Folstein S, Rutter M: Genetic influences and infantile autism. Nature 1977, 265:726-728.

12. Bailey A, Le Couteur A, Gottesman I, Bolton P, Simonoff E, Yuzda E, Rutter M: Autism as a strongly genetic disorder: evidence from a British twin study. Psychol Med 1995, 25:63-77.

13. Ritvo ER, Spence MA, Freeman BJ, Mason-Brothers A, Mo A, Marazita ML: Evidence for autosomal recessive inheritance in 46 families with multiple incidences of autism. Am J Psychiatry 1985, 142:187-192.

14. Steffenburg S, Gillberg C, Hellgren L, Andersson L, Gillberg IC, Jakobsson G, Bohman M: A twin study of autism in Denmark, Finland, Iceland, Norway and Sweden. J Child Psychol Psychiatry 1989, 30:405-416. 
15. Chakrabarti S, Fombonne E: Pervasive developmental disorders in preschool children. JAMA 2001, 285:3093-3099.

16. Smalley SL, Asarnow RF, Spence MA: Autism and genetics: a decade of research. Arch Gen Psychiatry 1988, 45:953-961.

17. Bailey A, Palferman S, Heavey L, Le Couteur A: Autism: the phenotype in relatives. J Autism Dev Disord 1998, 28:369-392.

18. Szatmari $P$, Jones MB, Zwaigenbaum L, MacLean JE: Genetics of autism: overview and new directions. J Autism Dev Disord 1998, 28:351-368.

19. Chudley AE, Gutierrez E, Jocelyn L, Chodriker BN: Outcomes of genetic evaluation in children with pervasive developmental disorder. J Dev Behav Pediatr 1998, 19:321-325.

20. Veenstra-Vanderweele J, Cook EH Jr, Lombroso PJ: Genetics of childhood disorders: XLVI. Autism, part 5: genetics of autism. J Am Acad Child Adolesc Psychiatry 2003, 42:116-118.

21. Bolton PF, Pickles A, Murphy M, Rutter M: Autism, affective and other psychiatric disorders: patterns of familial aggregation. Psychol Med 1998 28:385-395.

22. Piven J, Palmer P, Jacobi D, Childress D, Arndt S: Broader autism phenotype: evidence from a family history study of multiple-incidence autism families. Am J Psychiatry 1997, 154:185-190.

23. Ritvo ER, Jorde LB, Mason-Brothers A, Freeman BJ, Pingree $C$, Jones $M B$, McMahon WM, Petersen PB, Jenson WR, Mo A: The UCLA-University of Utah epidemiologic survey of autism: recurrence risk estimates and genetic counseling. Am J Psychiatry 1989, 146:1032-1036.

24. Jorde LB, Hasstedt SJ, Ritvo ER, Mason-Brothers A, Freeman BJ, Pingree C, McMahon WM, Petersen B, Jenson WR, Mo A: Complex segregation analysis of autism. Am J Hum Genet 1991, 49:932-938.

25. Ritvo ER, Freeman BJ, Mason-Brothers A, Mo A, Ritvo AM: Concordance for the syndrome of autism in $\mathbf{4 0}$ pairs of afflicted twins. Am J Psychiatry 1985, 142:74-77.

26. Bolton P, Macdonald H, Pickles A, Rios P, Goode S, Crowson M, Bailey A, Rutter M: A case-control family history study of autism. J Child Psychol Psychiatry 1994, 35:877-900.

27. Risch N, Spiker D, Lotspeich L, Nouri N, Hinds D, Hallmayer J, Kalaydjieva L, McCague P, Dimiceli S, Pitts T, Nguyen L, Yang J, Harper C, Thorpe D, Vermeer S, Young H, Hebert J, Lin A, Ferguson J, Chiotti C, Wiese-Slater S, Rogers T, Salmon B, Nicholas P, Petersen PB, Pingree C, McMahon W, Wong DL, Cavalli-Sforza LL, Kraemer HC, Myers RM: A genomic screen of autism: evidence for a multilocus etiology. Am J Hum Genet 1999, 65:493-507.

28. Steffenburg S, Gillberg CL, Steffenburg U, Kyllerman M: Autism in Angelman syndrome: a population-based study. Pediatr Neurol 1996, 14:131-136.

29. Smalley SL: Autism and tuberous sclerosis. J Autism Dev Disord 1998, 28:407-414.

30. Folstein SE, Rutter ML: Autism: familial aggregation and genetic implications. J Autism Dev Disord 1988, 18:3-30.

31. Brown WT, Jenkins EC, Cohen IL, Fisch GS, Wolf-Schein EG, Gross A, Waterhouse L, Fein D, Mason-Brothers A, Ritvo E: Fragile $X$ and autism: a multicenter survey. Am J Med Genet 1986, 23:341-352.

32. Folstein SE, Piven J: Etiology of autism: genetic influences. Pediatrics 1991, 87:767-773.

33. Bucan M, Abrahams BS, Wang K, Glessner JT, Herman El, Sonnenblick LI, Alvarez Retuerto Al, Imielinski M, Hadley D, Bradfield JP, Kim C, Gidaya NB, Lindquist I, Hutman T, Sigman M, Kustanovich V, Lajonchere CM, Singleton A, Kim J, Wassink TH, McMahon WM, Owley T, Sweeney JA, Coon H, Nurnberger JI, Li M, Cantor RM, Minshew NJ, Sutcliffe JS, Cook EH, et al: Genome-wide analyses of exonic copy number variants in a familybased study point to novel autism susceptibility genes. PLoS Genet 2009, 5:e1000536.

34. Sebat J, Lakshmi B, Malhotra D, Troge J, Lese-Martin C, Walsh T, Yamrom B, Yoon S, Krasnitz A, Kendall J, Leotta A, Pai D, Zhang R, Lee YH, Hicks J, Spence SJ, Lee AT, Puura K, Lehtimäki T, Ledbetter D, Gregersen PK, Bregman J, Sutcliffe JS, Jobanputra V, Chung W, Warburton D, King MC, Skuse D, Geschwind DH, Gilliam TC, et al: Strong association of de novo copy number mutations with autism. Science 2007, 316:445-449.

35. Pinto D, Pagnamenta AT, Klei L, Anney R, Merico D, Regan R, Conroy J, Magalhaes TR, Correia C, Abrahams BS, Almeida J, Bacchelli E, Bader GD, Bailey AJ, Baird G, Battaglia A, Berney T, Bolshakova N, Bolte S, Bolton PF, Bourgeron T, Brennan S, Brian J, Bryson SE, Carson AR, Casallo G, Casey J, Chung BH, Cochrane L, Corsello C, et al: Functional impact of global rare copy number variation in autism spectrum disorders. Nature 2010, 466:368-372.

36. Miller DT, Shen Y, Weiss LA, Korn J, Anselm I, Bridgemohan C, Cox GF, Dickinson H, Gentile J, Harris DJ, Hegde V, Hundley R, Khwaja O, Kothare S, Luedke C, Nasir R, Poduri A, Prasad K, Raffalli P, Reinhard A, Smith SE, Sobeih MM, Soul JS, Stoler J, Takeoka M, Tan WH, Thakuria J, Wolff R, Yusupov R, Gusella JF, et al: Microdeletion/duplication at 15q13.2q13.3 among individuals with features of autism and other neuropsychiatric disorders. J Med Genet 2009, 46:242-248.

37. Anney R, Klei L, Pinto D, Regan R, Conroy J, Magalhaes TR, Correia C, Abrahams BS, Sykes N, Pagnamenta AT, Almeida J, Bacchelli E, Bailey AJ, Baird G, Battaglia A, Berney T, Bolshakova N, Bolte S, Bolton PF, Bourgeron T, Brennan S, Brian J, Carson AR, Casallo G, Casey J, Chu SH, Cochrane L, Corsello C, Crawford EL, Crossett A, et al: A genome-wide scan for common alleles affecting risk for autism. Hum Mol Genet 2010, 19:4072-4082.

38. Scherer SW, Dawson G: Risk factors for autism: translating genomic discoveries into diagnostics. Hum Genet 2011, 130:123-148.

39. Betancur C: Etiological heterogeneity in autism spectrum disorders: more than 100 genetic and genomic disorders and still counting. Brain Res 2011, 1380:42-77.

40. Devlin B, Melhem N, Roeder K: Do common variants play a role in risk for autism? Evidence and theoretical musings. Brain Res 2011, 1380:78-84.

41. Hu W, Addington A, Hyman A: Novel autism subtype-dependent genetic variants are revealed by quantitative trait and subphenotype association analyses of published GWAS data. PLoS One 2011, 6:e19067.

42. Anney RJ, Kenny EM, O'Dushlaine C, Yaspan BL, Parkhomenka E, Buxbaum JD, Sutcliffe J, Gill M, Gallagher L, Bailey AJ, Fernandez BA, Szatmari P, Scherer SW, Patterson A, Marshall CR, Pinto D, Vincent JB, Fombonne E, Betancur C, Delorme R, Leboyer M, Bourgeron T, Mantoulan C, Roge B, Tauber M, Freitag CM, Poustka F, Duketis E, Klauck SM, The Autism Genome Project, et al: Gene-ontology enrichment analysis in two independent family-based samples highlights biologically plausible processes for autism spectrum disorders. Eur J Hum Genet 2011, 19:1082-1089.

43. Yaspan BL, Bush WS, Torstenson ES, Ma D, Pericak-Vance MA, Ritchie MD, Sutcliffe JS, Haines JL: Genetic analysis of biological pathway data through genomic randomization. Hum Genet 2011, 129:563-571.

44. Hussman JP, Chung RH, Griswold AJ, Jaworski JM, Salyakina D, Ma D, Konidari I, Whitehead PL, Vance JM, Martin ER, Cuccaro ML, Gilbert JR, Haines JL, Pericak-Vance MA: A noise-reduction GWAS analysis implicates altered regulation of neurite outgrowth and guidance in autism. Mol Autism 2011, 2:1.

45. Geschwind DH: Genetics of autism spectrum disorders. Trends Cogn Sci 2011, 15:409-416.

46. Cook EH Jr, Scherer SW: Copy-number variations associated with neuropsychiatric conditions. Nature 2008, 455:919-923.

47. State MW: The genetics of child psychiatric disorders: focus on autism and Tourette syndrome. Neuron 2010, 68:254-269.

48. Abrahams BS, Geschwind DH: Advances in autism genetics: on the threshold of a new neurobiology. Nat Rev Genet 2008, 9:341-355.

49. Freitag CM, Staal W, Klauck SM, Duketis E, Waltes R: Genetics of autistic disorders: review and clinical implications. Eur Child Adolesc Psychiatry 2010, 19:169-178.

50. Merikangas AK, Corvin AP, Gallagher L: Copy-number variants in neurodevelopmental disorders: promises and challenges. Trends Genet 2009, 25:536-544.

51. O'Roak BJ, State MW: Autism genetics: strategies, challenges, and opportunities. Autism Res 2008, 1:4-17.

52. Eapen V: Genetic basis of autism: is there a way forward? Curr Opin Psychiatry 2011, 24:226-236.

53. Hallmayer J, Cleveland S, Torres A, Phillips J, Cohen B, Torigoe T, Miller J, Fedele A, Collins J, Smith K, Lotspeich L, Croen LA, Ozonoff S, Lajonchere C, Grether JK, Risch N: Genetic heritability and shared environmental factors among twin pairs with autism. Arch Gen Psychiatry 2011, 68:1095-1102.

54. Ozonoff S, Young GS, Carter A, Messinger D, Yirmiya N, Zwaigenbaum L, Bryson S, Carver L, Constantino JN, Dobkins K, Hutman T, Iverson JM, Landa R, Rogers SJ, Sigman M, Stone WL: Recurrence risk for autism spectrum disorders: a Baby Siblings Research Consortium study. Pediatrics 2011, 128:e488-e495. 
55. Schanen NC: Epigenetics of autism spectrum disorders. Hum Mol Genet 2006, 15(Spec No 2):R138-R150.

56. Grafodatskaya D, Chung B, Szatmari P, Weksberg R: Autism spectrum disorders and epigenetics. J Am Acad Child Adolesc Psychiatry 2010, 49:794-809.

57. Bjornsson HT, Cui H, Gius D, Fallin MD, Feinberg AP: The new field of epigenomics: implications for cancer and other common disease research. Cold Spring Harb Symp Quant Biol 2004, 69:447-456.

58. Chess S: Autism in children with congenital rubella. J Autism Child Schizophr 1971, 1:33-47.

59. Chess S: Follow-up report on autism in congenital rubella. J Autism Child Schizophr 1977, 7:69-81.

60. Yamashita Y, Fujimoto C, Nakajima E, Isagai T, Matsuishi T: Possible association between congenital cytomegalovirus infection and autistic disorder. J Autism Dev Disord 2003, 33:455-459.

61. Rodier PM, Ingram JL, Tisdale B, Croog VJ: Linking etiologies in humans and animal models: studies of autism. Reprod Toxicol 1997, 11:417-422.

62. Christianson AL, Chesler N, Kromberg JG: Fetal valproate syndrome: clinical and neuro-developmental features in two sibling pairs. Dev Med Child Neurol 1994, 36:361-369.

63. Williams PG, Hersh JH: A male with fetal valproate syndrome and autism. Dev Med Child Neurol 1997, 39:632-634.

64. Moore SJ, Turnpenny P, Quinn A, Glover S, Lloyd DJ, Montgomery T, Dean JCS: A clinical study of 57 children with fetal anticonvulsant syndromes. J Med Genet 2000, 37:489-497.

65. Croen LA, Connors SL, Matevia M, Qian Y, Newschaffer C, Zimmerman AW: Prenatal exposure to $\beta 2$-adrenergic receptor agonists and risk of autism spectrum disorders. J Neurodev Disord 2011, 3:307-315.

66. Croen LA, Grether JK, Yoshida CK, Odouli R, Hendrick V: Antidepressant use during pregnancy and childhood autism spectrum disorders. Arch Gen Psychiatry 2011, 68:1104-1112.

67. Atladóttir HO, Thorsen P, Østergaard L, Schendel DE, Lemcke S, Abdallah M, Parner ET: Maternal infection requiring hospitalization during pregnancy and autism spectrum disorders. J Autism Dev Disord 2010, 40:1423-1430.

68. Goines PE, Croen LA, Braunschweig D, Yoshida CK, Grether J, Hansen R, Kharrazi M, Ashwood P, Van de Water J: Increased midgestational IFN- $\gamma$, IL-4 and IL-5 in women bearing a child with autism: a case-control study. Mol Autism 2011, 2:13.

69. Voineagu I, Wang X, Johnston P, Lowe JK, Tian Y, Horvath S, Mill J, Cantor RM, Blencowe BJ, Geschwind DH: Transcriptomic analysis of autistic brain reveals convergent molecular pathology. Nature 2011, 474:380-384

70. Vargas DL, Nascimbene C, Krishnan C, Zimmerman AW, Pardo CA: Neuroglial activation and neuroinflammation in the brain of patients with autism. Ann Neurol 2005, 57:67-81.

71. Gardener H, Spiegelman D, Buka SL: Prenatal risk factors for autism: comprehensive meta-analysis. Br J Psychiatry 2009, 195:7-14

72. Gardener H, Spiegelman D, Buka SL: Perinatal and neonatal risk factors for autism: a comprehensive meta-analysis. Pediatrics 2011, 128:344-355

73. Kolevzon A, Gross R, Reichenberg A: Prenatal and perinatal risk factors for autism: a review and integration of findings. Arch Pediatr Adolesc Med 2007, 161:326-333

74. Sasanfar R, Haddad SA, Tolouei A, Ghadami M, Yu D, Santangelo SL: Paternal age increases the risk for autism in an Iranian population sample. Mol Autism 2010, 1:2.

75. Shelton JF, Tancredi DJ, Hertz-Picciotto I: Independent and dependent contributions of advanced maternal and paternal ages to autism risk. Autism Res 2010, 3:30-39.

76. Grether JK, Anderson MC, Croen LA, Smith D, Windham GC: Risk of autism and increasing maternal and paternal age in a large North American population. Am J Epidemiol 2009, 170:1118-1126.

77. King MD, Fountain C, Dakhlallah D, Bearman PS: Estimated autism risk and older reproductive age. Am J Public Health 2009, 99:1673-1679.

78. Durkin MS, Maenner MJ, Newschaffer CJ, Lee LC, Cunniff CM, Daniels JL, Kirby RS, Leavitt L, Miller L, Zahorodny W, Schieve LA: Advanced parental age and the risk of autism spectrum disorder. Am J Epidemiol 2008, 168:1268-1276.

79. Croen LA, Najjar DV, Fireman B, Grether JK: Maternal and paternal age and risk of autism spectrum disorders. Arch Pediatr Adolesc Med 2007, 161:334-340.
80. Reichenberg A, Gross R, Weiser M, Bresnahan M, Silverman J, Harlap S, Rabinowitz J, Shulman C, Malaspina D, Lubin G, Knobler HY, Davidson M, Susser E: Advancing paternal age and autism. Arch Gen Psychiatry 2006, 63:1026-1032.

81. Cheslack-Postava K, Liu K, Bearman PS: Closely spaced pregnancies are associated with increased odds of autism in California sibling births. Pediatrics 2011, 127:246-253.

82. Schmidt RJ, Hansen RL, Hartiala J, Allayee H, Schmidt LC, Tancredi DJ, Tassone F, Hertz-Picciotto I: Prenatal vitamins, one-carbon metabolism gene variants, and risk for autism. Epidemiology 2011, 22:476-485.

83. Palmer RF, Blanchard S, Stein Z, Mandell D, Miller C: Environmental mercury release, special education rates, and autism disorder: an ecological study of Texas. Health Place 2006, 12:203-209.

84. Windham GC, Zhang L, Gunier R, Croen LA, Grether JK: Autism spectrum disorders in relation to distribution of hazardous air pollutants in the San Francisco Bay area. Environ Health Perspect 2006, 114:1438-1444.

85. Kalkbrenner AE, Daniels JL, Chen JC, Poole C, Emch M, Morrissey J: Perinatal exposure to hazardous air pollutants and autism spectrum disorders at age 8. Epidemiology 2010, 21:631-641.

86. Volk HE, Hertz-Picciotto I, Delwiche L, Lurmann F, McConnell R: Residential proximity to freeways and autism in the CHARGE study. Environ Health Perspect 2011, 119:873-877.

87. Roberts EM, English PB, Grether JK, Windham GC, Somberg L, Wolff C: Maternal residence near agricultural pesticide applications and autism spectrum disorders among children in the California Central Valley. Environ Health Perspect 2007, 115:1482-1489.

88. Eskenazi B, Huen K, Marks A, Harley KG, Bradman A, Barr DB, Holland N: PON1 and neurodevelopment in children from the CHAMACOS study exposed to organophosphate pesticides in utero. Environ Health Perspect 2010, 118:1775-1781.

89. Rauh VA, Garfinkel R, Perera FP, Andrews HF, Hoepner L, Barr DB, Whitehead R, Tang D, Whyatt RW: Impact of prenatal chlorpyrifos exposure on neurodevelopment in the first 3 years of life among innercity children. Pediatrics 2006, 118:e1845-e1859.

90. Engel SM, Wetmur J, Chen J, Zhu C, Barr DB, Canfield RL, Wolff MS: Prenatal exposure to organophosphates, paraoxonase 1, and cognitive development in childhood. Environ Health Perspect 2011, 119:1182-1188.

91. Bouchard MF, Chevrier J, Harley KG, Kogut K, Vedar M, Calderon N, Trujillo C, Johnson C, Bradman A, Barr DB, Eskenazi B: Prenatal exposure to organophosphate pesticides and IQ in 7-year-old children. Environ Health Perspect 2011, 119:1189-1195.

92. Rodier PM, Ingram JL, Tisdale B, Nelson S, Romano J: Embryological origin for autism: developmental anomalies of the cranial nerve motor nuclei. $J$ Comp Neurol 1996, 370:247-261.

93. Bauman ML, Kemper TL: Neuroanatomic observations of the brain in autism: a review and future directions. Int I Dev Neurosci 2005, 23:183-187.

94. Kemper TL, Bauman M: Neuropathology of infantile autism. J Neuropathol Exp Neurol 1998, 57:645652

95. Acosta MT, Pearl PL: The neurobiology of autism: new pieces of the puzzle. Curr Neurol Neurosci Rep 2003, 3:149-156.

96. Schumann CM, Bloss CS, Barnes CC, Wideman GM, Carper RA Akshoomoff N, Pierce K, Hagler D, Schork N, Lord C, Courchesne E: Longitudinal magnetic resonance imaging study of cortical development through early childhood in autism. J Neurosci 2010, 30:4419-4427.

97. Hazlett HC, Poe MD, Gerig G, Styner M, Chappell C, Smith RG, Vachet C, Piven J: Early brain overgrowth in autism associated with an increase in cortical surface area before age 2 years. Arch Gen Psychiatry 2011, 68:467-476.

98. Johnson MB, Kawasawa YI, Mason CE, Krsnik Z, Coppola G, Bogdanović D, Geschwind DH, Mane SM, State MW, Sestan N: Functional and evolutionary insights into human brain development through global transcriptome analysis. Neuron 2009, 62:494-509.

99. Rice D, Barone $\mathrm{S} \mathrm{Jr}$ : Critical periods of vulnerability for the developing nervous system: evidence from humans and animal models. Environ Health Perspect 2000, 108(Suppl 3):511-533.

100. Rodier PM: Environmental causes of central nervous system maldevelopment. Pediatrics 2004, 113:1076-1083. 
101. Persico AM, Bourgeron T: Searching for ways out of the autism maze: genetic, epigenetic and environmental clues. Trends Neurosci 2006, 29:349-358.

102. Toro R, Konyukh M, Delorme R, Leblond C, Chaste P, Fauchereau F, Coleman M, Leboyer M, Gillberg C, Bourgeron T: Key role for gene dosage and synaptic homeostasis in autism spectrum disorders. Trends Genet 2010, 26:363-372.

103. Connors SL, Levitt P, Matthews SG, Slotkin TA, Johnston MV, Kinney HC, Johnson WG, Dailey RM, Zimmerman AW: Fetal mechanisms in neurodevelopmental disorders. Pediatr Neurol 2008, 38:163-176.

104. Royland JE, Kodavanti PR: Gene expression profiles following exposure to a developmental neurotoxicant, Aroclor 1254: pathway analysis for possible mode(s) of action. Toxicol Appl Pharmacol 2008, 231:179-196.

105. Augustine-Rauch KA, Zhang QJ, Posobiec L, Mirabile R, DeBoer LS, Solomon HM, Wier PJ: SB-236057: Critical window of sensitivity study and embryopathy of a potent musculoskeletal teratogen. Birth Defects Res $A$ Clin Mol Teratol 2004, 70:773-788.

106. Szatmari P, Jones MB, Tuff L, Bartolucci G, Fisman S, Mahoney W: Lack of cognitive impairment in first-degree relatives of children with pervasive developmental disorders. J Am Acad Child Adolesc Psychiatry 1993, 32:1264-1273

107. Autism and Developmental Disabilities Monitoring Network Surveillance Year 2006 Principal Investigators, Centers for Disease Control and Prevention (CDC): Prevalence of autism spectrum disorders: Autism and Developmental Disabilities Monitoring Network, United States, 2006. MMWR Surveill Summ 2009, 58(SS10):1-20.

108. Toth K, Dawson G, Meltzoff AN, Greenson J, Fein D: Early social, imitation, play, and language abilities of young non-autistic siblings of children with autism. J Autism Dev Disord 2007, 37:145-157.

109. Lord C, Rutter M, Le Couteur A: Autism Diagnostic Interview-Revised: a revised version of a diagnostic interview for caregivers of individuals with possible pervasive developmental disorders. J Autism Dev Disord 1994, 24:659-685.

110. Lord C, Risi S, Lambrecht L, Cook EH Jr, Leventhal BL, DiLavore PC, Pickles A, Rutter M: The Autism Diagnostic Observation Schedule-Generic: a standard measure of social and communication deficits associated with the spectrum of autism. J Autism Dev Disord 2000, 30:205-223.

111. Weinberg CR, Shore DL, Umbach DM, Sandler DP: Using risk-based sampling to enrich cohorts for endpoints, genes, and exposures. Am J Epidemiol 2007, 166:447-455.

112. Constantino JN, Todd RD: Autistic traits in the general population: a twin study. Arch Gen Psychiatry 2003, 60:524-530.

113. Ronald A, Happe F, Price TS, Baron-Cohen S, Plomin R: Phenotypic and genetic overlap between autistic traits at the extremes of the general population. J Am Acad Child Adolesc Psychiatry 2006, 45:1206-1214.

114. Skuse DH, Mandy W, Steer C, Miller LL, Goodman R, Lawrence K, Emond A, Golding J: Social communication competence and functional adaptation in a general population of children: preliminary evidence for sex-byverbal IQ differential risk. J Am Acad Child Adolesc Psychiatry 2009, 48:128-137.

115. Bryson SE, Zwaigenbaum L, McDermott C, Rombough V, Brian J: The Autism Observation Scale for Infants: scale development and reliability data. J Autism Dev Disord 2008, 38:731-738.

116. Mullen EM: Mullen Scales of Early Learning San Antonio, TX: Pearson Education; 1995

117. Bishop SL, Guthrie W, Coffing M, Lord C: Convergent validity of the Mullen Scales of Early Learning and the differential ability scales in children with autism spectrum disorders. Am J Intellect Dev Disabil 2011, 116:331-343.

118. Rozga A, Hutman T, Young GS, Rogers SJ, Ozonoff S, Dapretto M, Sigman M: Behavioral profiles of affected and unaffected siblings of children with autism: contribution of measures of mother-infant interaction and nonverbal communication. J Autism Dev Disord 2011, 41:287-301.

119. Flanagan J, Landa R, Bauman M: Head lag in infants at risk for autism: a preliminary study. Am J Occup Ther

120. Newport DJ, Brennan PA, Green P, llardi D, Whitfield TH, Morris N, Knight BT, Stowe ZN: Maternal depression and medication exposure during pregnancy: comparison of maternal retrospective recall to prospective documentation. BJOG 2008, 115:681-688.
121. Voldsgaard P, Schiffman J, Mednick S, Rodgers B, Christensen H, Bredkjær S, Schulsinger F: Accuracy of retrospective reports of infections during pregnancy. Int J Methods Psychiatr Res 2002, 11:184-186.

122. Werler MM, Pober BR, Nelson K, Holmes LB: Reporting accuracy among mothers of malformed and nonmalformed infants. Am J Epidemiol 1989, 129:415-421.

123. Langholz B, Thomas DC: Nested case-control and case-cohort methods of sampling from a cohort: a critical comparison. Am J Epidemiol 1990, 131:169-176

124. Steenland K, Deddens JA: Increased precision using countermatching in nested case-control studies. Epidemiology 1997, 8:238-242.

125. Schaubel D, Hanley J, Collet JP, Bolvin JF, Sharpe C, Morrison HI, Mao Y: Two-stage sampling for etiologic studies: sample size and power. Am J Epidemiol 1997, 146:450-458.

126. Spiegelman D, Gray R: Cost-efficient study designs for binary response data with Gaussian covariate measurement error. Biometrics 1991, 47:851-869.

127. Early Autism Risk Longitudinal Investigation (EARLI) Study. [https://www. facebook.com/The.EARLI.Study].

128. All about the EARLI Study. [http://www.youtube.com/watch? $v=F d F x e h V p Z H 4 \& \mid r=1]$

129. Early Autism Risk Longitudinal Investigation. [http://www.earlistudy.org].

130. Julien R, Adamkiewicz G, Levy Jl, Bennett D, Nishioka M, Spengler JD: Pesticide loadings of select organophosphate and pyrethroid pesticides in urban public housing. J Expo Sci Environ Epidemiol 2008, 18:167-174.

131. Allen JG, McClean MD, Stapleton HM, Webster TF: Critical factors in assessing exposure to PBDEs via house dust. Environ Int 2008 34:1085-1091.

132. Vojta PJ, Friedman W, Marker DA, Clickner R, Rogers JW, Viet SM, Muilenberg ML, Thorne PS, Arbes SJ Jr, Zeldin DC: First National Survey of Lead and Allergens in Housing: survey design and methods for the allergen and endotoxin components. Environ Health Perspect 2002, 110:527-532.

133. Rudel RA, Camann DE, Spengler JD, Korn LR, Brody JG: Phthalates, alkylphenols, pesticides, polybrominated diphenyl ethers, and other endocrine-disrupting compounds in indoor air and dust. Environ Sci Technol 2003, 37:4543-4553.

134. Wu N, Herrmann T, Paepke O, Tickner J, Hale R, Harvey LE, La Guardia M, McClean MD, Webster TF: Human exposure to PBDEs: associations of PBDE body burdens with food consumption and house dust concentrations. Environ Sci Technol 2007, 41:1584-1589.

135. Colt JS, Davis S, Severson RK, Lynch CF, Cozen W, Camann D, Engels EA Blair A, Hartge P: Residential insecticide use and risk of non-Hodgkin's lymphoma. Cancer Epidemiol Biomarkers Prev 2006, 15:251-257.

136. Colt JS, Rothman N, Severson RK, Hartge P, Cerhan JR, Chatterjee N, Cozen W, Morton LM, De Roos AJ, Davis S, Chanock S, Wang SS: Organochlorine exposure, immune gene variation, and risk of nonHodgkin lymphoma. Blood 2009, 113:1899-1905.

137. Colt JS, Severson RK, Lubin J, Rothman N, Camann D, Davis S, Cerhan JR, Cozen W, Hartge P: Organochlorines in carpet dust and non-Hodgkin lymphoma. Epidemiology 2005, 16:516-525.

138. Thorne PS, Kulhankova K, Yin M, Cohn R, Arbes SJ Jr, Zeldin DC: Endotoxin exposure is a risk factor for asthma: the national survey of endotoxin in United States housing. Am J Respir Crit Care Med 2005, 172:1371-1377.

139. Bornehag CG, Sundell J, Weschler CJ, Sigsgaard T, Lundgren B, Hasselgren M, Hägerhed-Engman L: The association between asthma and allergic symptoms in children and phthalates in house dust: a nested case-control study. Environ Health Perspect 2004, 112:1393-1397.

140. Georgiades S, Szatmari P, Zwaigenbaum L, Bryson SE, Brian J, Roberts W, Smith IM, Vaillancourt T, Roncadin C: A prospective study of sub-threshold autistic-like traits in unaffected siblings of children with autism spectrum disorder [abstract 128.004]. Presented at the International Meeting for Autism Research, 13 San Diego USA: CA 2011.

141. Kim SH, Lord C: Combining information from multiple sources for the diagnosis of autism spectrum disorders for toddlers and young preschoolers from 12 to 47 months of age. J Child Psychol Psychiatry 2012, 53:143-151.

142. Gotham K, Pickles A, Lord C: Standardizing ADOS scores for a measure of severity in autism spectrum disorders. J Autism Dev Disord 2009, 39:693-705. 
143. Constantino JN, Davis SA, Todd RD, Schindler MK, Gross MM, Brophy SL, Metzger LM, Shoushtari CS, Splinter R, Reich W: Validation of a brief quantitative measure of autistic traits: comparison of the Social Responsiveness Scale with the Autism Diagnostic Interview-Revised. Autism Dev Disord 2003, 33:427-433.

144. Bolte S, Poustka F, Constantino JN: Assessing autistic traits: cross-cultural validation of the Social Responsiveness Scale (SRS). Autism Res 2008, 1:354-363

145. Virkud YV, Todd RD, Abbacchi AM, Zhang Y, Constantino JN: Familial aggregation of quantitative autistic traits in multiplex versus simplex autism. Am J Med Genet B Neuropsychiatr Genet 2009, 150B:328-334.

146. Constantino JN, Zhang Y, Frazier T, Abbacchi AM, Law P: Sibling recurrence and the genetic epidemiology of autism. Am J Psychiatry 2010, 167:1349-1356.

147. Akshoomoff N: Use of the Mullen Scales of Early Learning for the assessment of young children with autism spectrum disorders. Child Neuropsychol 2006, 12:269-277.

148. Szatmari P, Merette C, Emond C, Zwaigenbaum L, Jones MB, Maziade M, Roy MA, Palmour R: Decomposing the autism phenotype into familial dimensions. Am J Med Genet B Neuropsychiatr Genet 2008, 147B:3-9.

149. Sparrow SS, Balla DA, Cicchetti DV, Bella DA: Vineland Adaptive Behavior Scale-ll San Antonio, TX: Pearson Education; 2005.

150. Fenton G, D'Ardia C, Valente D, Del Vecchio I, Fabrizi A, Bernabei P: Vineland Adaptive Behavior profiles in children with autism and moderate to severe developmental delay. Autism 2003, 7:269-287.

151. Wetherby AM, Prizant BM: Communication and Symbolic Behavior Scales Developmental Profile (CSBS DP) Baltimore: Paul H. Brookes Publishing Co; 2002.

152. Eadie PA, Ukoumunne O, Skeat J, Prior MR, Bavin E, Bretherton L, Reilly S: Assessing early communication behaviours: structure and validity of the Communication and Symbolic Behaviour Scales-Developmental Profile (CSBS-DP) in 12-month-old infants. Int J Lang Commun Disord 2010, 45:572-585.

153. Luyster R, Lopez K, Lord C: Characterizing communicative development in children referred for autism spectrum disorders using the MacArthurBates Communicative Development Inventory (CDI). J Child Lang 2007, 34:623-654.

154. MacArthur-Bates Communicative Development Inventories. [http://www. sci.sdsu.edu/cdi/].

155. Little LM, Freuler AC, Houser MB, Guckian L, Carbine K, David FJ, Baranek GT: Psychometric validation of the Sensory Experiences Questionnaire. Am J Occup Ther 2011, 65:207-210.

156. Garon N, Bryson SE, Zwaigenbaum L, Smith IM, Brian J, Roberts W, Szatmari P: Temperament and its relationship to autistic symptoms in a high-risk infant sib cohort. J Abnorm Child Psychol 2009, 37:59-78.

157. Rothbart MK: Measurement of temperament in infancy. Child Dev 1981, 52:569-578.

158. Achenbach TM: Achenbach System of Empirically Based Assessment (ASEBA): Development, Findings, Theory, and Applications Burlington, VT: University of Vermont, Research Center for Children, Youth, \& Families; 2009 [http://www. aseba.org].

159. Pandolfi V, Magyar Cl, Dill CA: Confirmatory factor analysis of the Child Behavior Checklist 1.5-5 in a sample of children with autism spectrum disorders. J Autism Dev Disord 2009, 39:986-995.

160. Centers for Disease Control and Prevention (CDC): Autism Spectrum Disorders: (ASDs): Study to Explore Early Development (SEED).[http:// www.cdc.gov/ncbddd/autism/seed.html].

161. UC Davis MIND Institute: Current Research Studies.[http://www.ucdmc. ucdavis.edu/mindinstitute/research/esdm/currentprojects.html].

162. Brain Development in Autism: Infant Siblings. [http://www.ibisnetwork. org].

163. Torrey EF, Dhavale D, Lawlor JP, Yolken RH: Autism and head circumference in the first year of life. Biol Psychiatry 2004, 56:892-894.

164. Heikura U: Intellectual Disability in the Northern Finland Birth Cohort 1986 Oulu, Finland: Oulu University Press; 2008 [http://herkules.oulu.fi/ isbn9789514287114/isbn9789514287114.pdf]

165. Williams E, Thomas K, Sidebotham H, Emond A: Prevalence and characteristics of autistic spectrum disorders in the ALSPAC cohort. Dev Med Child Neurol 2008, 50:672-677.

166. Eliasen M, Tolstrup JS, Nybo Andersen AM, Grønbæk M, Olsen J, Strandberg-Larsen K: Prenatal alcohol exposure and autistic spectrum disorders: a population-based prospective study of 80,552 children and their mothers. Int J Epidemiol 2010, 39:1074-1081.

167. Stoltenberg C, Schjølberg S, Bresnahan M, Hornig M, Hirtz D, Dahl C, Lie KK, Reichborn-Kjennerud T, Schreuder $P$, Alsaker E, Oyen AS, Magnus P, Surén P, Susser E, Lipkin WI, ABC Study Group: The Autism Birth Cohort: a paradigm for gene-environment-timing research. Mol Psychiatry 2010, 15:676-680.

168. Tsuchiya K, Matsumoto K, Suda S, Miyachi T, Itoh H, Kanayama N, Hirano K, Ohzeki T, Takei N, HBC Study Team: Searching for very early precursors of autism spectrum disorders: the Hamamatsu Birth Cohort for Mothers and Children (HBC). J Dev Orig Health Dis 2010, 1:158-173.

169. Magnus P, Irgens LM, Haug K, Nystad W, Skjærven R, Stoltenberg C, MoBa Study Group: Cohort profile: the Norwegian Mother and Child Cohort Study (MoBa). Int J Epidemiol 2006, 35:1146-1150.

170. Hertz-Picciotto I, Croen LA, Hansen R, Jones CR, van de Water J, Pessah IN The CHARGE study: an epidemiologic investigation of genetic and environmental factors contributing to autism. Environ Health Perspect 2006, 114:1119-1125.

171. Schendel DE, DiGuiseppi $C$, Croen LA, Fallin MD, Reed PL, Schieve LA, Wiggins LD, Daniels J, Grether J, Levy SE, Miller L, Newschaffer C, PintoMartin J, Robinson C, Windham GC, Alexander A, Aylsworth AS, Bernal P, Bonner JD, Blaskey L, Bradley C, Collins J, Ferretti CJ, Farzadegan H, Giarelli E, Harvey M, Hepburn S, Herr M, Kaparich K, Landa R, et al: The Study to Explore Early Development (SEED): a multisite epidemiologic study of autism by the Centers for Autism Developmental Disabilities Research and Epidemiology (CADDRE) Network1. J Autism Dev Disord doi:10.1007/s10803-012-1461-8.

doi:10.1186/1866-1955-4-7

Cite this article as: Newschaffer et al:: Infant siblings and the investigation of autism risk factors. Journal of Neurodevelopmental Disorders 2012 4:7

\section{Submit your next manuscript to BioMed Central and take full advantage of:}

- Convenient online submission

- Thorough peer review

- No space constraints or color figure charges

- Immediate publication on acceptance

- Inclusion in PubMed, CAS, Scopus and Google Scholar

- Research which is freely available for redistribution

Submit your manuscript at www.biomedcentral.com/submit
C) Biomed Central 